\title{
Transcription factors and target genes of pre-TCR signaling
}

\author{
Cristina López-Rodríguez $1,3, *$ \\ Email cristina.lopez-rodriguez@upf.edu \\ Jose Aramburu 1 \\ Rosa Berga-Bolaños 1,2 \\ 1 Immunology Unit, Department of Experimental and Health Sciences, Universitat Pompeu Fabra, Barcelona, Spain \\ 2 Present Address: Immune Cells and Inflammation Section, National Institute on Aging, National Institutes of \\ Health, Baltimore, MD, USA \\ 3 Barcelona Biomedical Research Park, C/Doctor Aiguader Nº8, 08003 Barcelona, Spain
}

\begin{abstract}
Almost 30 years ago pioneering work by the laboratories of Harald von Boehmer and Susumo Tonegawa provided the first indications that developing thymocytes could assemble a functional TCR $\beta$ chain-containing receptor complex, the pre-TCR, before TCR $\alpha$ expression. The discovery and study of the pre-TCR complex revealed paradigms of signaling pathways in control of cell survival and proliferation, and culminated in the recognition of the multifunctional nature of this receptor. As a receptor integrated in a dynamic developmental process, the pre-TCR must be viewed not only in the light of the biological outcomes it promotes, but also in context with those molecular processes that drive its expression in thymocytes. This review article focuses on transcription factors and target genes activated by the pre-TCR to drive its different outcomes.
\end{abstract}

\section{Keywords}

Thymocyte development
Pre-TCR expression
Pre-TCR signaling
Transcription factor
Gene expression
NF-kB
NFATc
NFAT5
ETS1
E2A/HEB proteins
Bcl2A1
p53
Intrinsic apoptotic pathway

We apologize to those authors whose work was not cited due to space limitations or our oversight.

\section{The thymus as the place for T cell development: short overview of thymocyte development}

The thymus is the organ that supports the differentiation and selection of $\mathrm{T}$ cells. The thymic stroma promotes $\mathrm{T}$ cell development by producing growth factors and ligands for receptors expressed in thymocytes. During mouse embryogenesis, the thymic rudiment differentiates into the cortical and medullary thymic epithelial cell subsets (cTECs and mTECs), the major constituents of thymic stroma [1]. Only a small subset of hematopoietic precursors with T-lineage potential is able to enter the thymus [2-4]. Early lymphoid progenitors (ELPs) enter the thymus at the cortico-medullary junction [5] and begin their development into $\mathrm{T}$ cells through several phenotypically distinct and sequential stages, known as double-negative (DN), double-positive (DP) and singlepositive (SP) based on the surface expression of the co-receptors CD4 and CD8. DN cells are further divided into four consecutive stages on the basis of CD44 and CD25 expression: DN1 (CD44 $\left.{ }^{+} \mathrm{CD} 25^{-}\right)$, DN2 (CD44 $\left.{ }^{+} \mathrm{CD} 25^{+}\right), \mathrm{DN} 3\left(\mathrm{CD} 44^{-} \mathrm{CD} 25^{+}\right)$and $\mathrm{DN} 4$ $\left(\mathrm{CD} 44^{-} \mathrm{CD} 25^{-}\right)$cells $[6]$.

Initial thymocyte development from DN1 to DN3 is promoted by molecules produced by cTECs, mainly interleukin-7 (IL-7) and Notch ligands [ 7, 8]. ELPs that home into the thymus retain the expression of the surface receptor c-kit [9], indeed a small subset of early thymocyte progenitors (EPs) defined within DN1 prothymocytes still has high expression of c-kit [ 10]. DN thymocytes move to the subcapsular region of the thymic cortex and express the pre-T-cell receptor (pre-TCR) complex [11, 12]. The pre-TCR is a unique molecular complex with an invariant pre-TCR $\alpha(\mathrm{pT} \alpha)$ chain associated with a recombined TCR $\beta$ chain and the signaling 
molecules $\mathrm{CD} 3 \gamma, \mathrm{CD} 3 \delta, \mathrm{CD} 3 \varepsilon$ and $\mathrm{CD} 3 \zeta$, which also form part of the mature TCR $[12,13]$. The pre-TCR, along with the DeltaNotch interaction [14], initiates the signals for further development to DP thymocytes that express $\alpha \beta T C R$ antigen receptors.

The TCR of cortical DP cells interacts with peptide-MHC complexes in stromal cells (cTECs and dendritic cells (DCs)) and the outcome of these interactions is the positive and negative selection of thymocytes. This results in the selection and survival of thymocytes that are potentially reactive to foreign antigens but tolerant to self-antigens, and therefore prevents autoimmune responses. Positively selected DP thymocytes then start relocating to the medulla and differentiate into T-helper or central regulatory $\mathrm{CD}^{+} \mathrm{SP}$ thymocytes that have the ability to recognize peptides presented by MHC class II molecules, or T-cytotoxic $\mathrm{CD} 8^{+} \mathrm{SP}$ thymocytes that can interact with MHC class I molecules.

SP thymocytes spend approximately 12 days in the medulla before being exported from the thymus. During this period, they undergo a maturation process to become mature and naïve SP thymocytes (CD62 L $\left.{ }^{\text {hi }} \mathrm{CD} 69^{\text {low }}\right)$. SP thymocytes are exported to the circulation through the perivascular space, which is channeled to post-capillary venules, arterioles and lymphatic vessels.

Thymocyte development, and more specifically their crossing through the pre-TCR-induced $\beta$-selection stage, is regulated by numerous transcriptions factors whose target gene products in turn control thymocyte maturation and also balance cell death and survival. In this article we review the nature, expression and function of different transcription regulators and their target genes that act to establish T-cell lineage commitment and the pre-TCR function.

\section{Transcription factors in control of T-cell identity during development}

Acquisition of T-cell-lineage identity includes both specification, which confers T-cell-specific functions, and commitment or loss of the ability to adopt alternative developmental fates. T-cell identity genes, as well as the transcription factors that regulate their expression, are turned on in a precise order [15] (Table 1). The composition of functional transcription factors shifts with each developmental transition of thymocytes, and the same transcription factor can have different roles at different stages. Transcription factors that are important for $\mathrm{T}$ cell development include T-cell identity factors, such as Notch, and non-lineage-specific regulators that play essential roles in $\mathrm{T}$ cell development [16].

Table 1

\begin{tabular}{|l|l|}
\hline Transcription factors regulating T lymphocyte commitment & Transcription factors that induce their gene expression \\
\hline Notch & E proteins \\
\hline TCF-1 & Notch, TCF-1 \\
\hline GATA-3 & Notch, TCF-1, Bcl11b, E proteins \\
\hline Bc11 1b & Notch, TCF-1, GATA-3, Runx 1 \\
\hline Id2/Id3 & TCR signaling, NFATc, Egr1 \\
\hline Ets1 & Notch \\
\hline
\end{tabular}

AQ1

T-cell lineage-restricted transcription factors regulating $\mathrm{T}$ cell specification

GATA-3

The zinc-finger transcription factor GATA-3 is highly expressed in mature T cells and natural killer (NK) cells. During T cell development, GATA-3 is a key lineage specification and commitment factor whose expression gradually increases from DN1 to DN3 stages, then diminishes at the DN4 stage, and is increased again at the DP stage, becoming upregulated in the CD4 ${ }^{+}$SP population, but not in $\mathrm{CD}^{+} \mathrm{SP}$ cells [17]. Gata3 expression is regulated by Notch, TCF-1, and Bcl11b [18]. E proteins have different roles in regulating GATA-3. The E2A protein E47 induces its expression [19, 20 ], facilitating Notch signaling that turns on Gata3 and protects it from PU.1 inhibition [21 ]. In addition, E2A proteins oppose IL-7R signaling and limit the expression of GATA-3 to restrain self-renewal and to prevent an arrest in differentiation [22].

AQ2

GATA-3 has crucial dose-dependent roles in early T cell survival, growth, specification and commitment [23]. While its overexpression in T-lineage precursors converts them to mast cells [24], lack of GATA-3 affects the expression of T-lineage commitment genes such as Bcl11b or Cd3e [25]. Moreover, GATA-3 directly regulates the expression of proteins that control T cell development, such as recombination activating gene (RAG) [26] and Th-POZ-Krüppel-like factor (Th-POK), a CD4-cell specifying transcription factor [27].

TCF-1, a Wnt signaling pathway transcription factor 
Wnt factors are soluble glycoproteins secreted by thymic epithelial cells. In its canonical pathway, Wnt-mediated signaling is initiated when Wnt binds to Frizzled receptors and the low-density lipoprotein receptor-related protein (LRP)-5 and LRP-6 on the cell surface of thymocytes [28]. The signaling cascade, involving blockade of GSK-3 $\beta$, stabilizes cytoplasmic $\beta$-catenin, which translocates into the nucleus and displaces the co-repressor Groucho from T-cell factor 1 (TCF-1, encoded by Tcf7) and lymphoid enhancer factor 1 (LEF1) high mobility group (HMG) box transcription factors. LEF1 is partially redundant with TCF-1 [29]. The expression of TCF-1 is restricted to T cells and precedes the expression of intracellular CD3 [30]. TCF-1 is directly activated by Notch during lymphocyte development and reaches its highest expression across the $\beta$-selection checkpoint and immature singlepositive CD8 cells $[31-33]$.

In T cell development, the Wnt signaling pathway promotes survival, expansion and differentiation of thymocytes [28]. TCF-1 targets the key T-cell lineage transcription factor genes Bcl11b, Gata3 and Tcf7 [32 ]. TCF-1 deficiency affects the highly proliferative stages DN2 and DN4 [34], and conditional deletion of $\beta$-catenin inhibits T cell development at the $\beta$-selection checkpoint in DN3 cells [35]. By contrast, activation of the pathway by in vivo stabilization of $\beta$-catenin results in thymocyte development to DP cells in the absence of pre-TCR signaling and TCR selection [36]. In addition to mediating Wnt-dependent signals, $\beta$-catenin functions downstream of other pathways and for instance, it is stabilized by signaling from both the pre-TCR and the mature TCR [37].

\section{Bcl11b}

$\mathrm{Bcl1} 1 \mathrm{~b}$ is a $\mathrm{C} 2 \mathrm{H} 2$-type zinc-finger transcription factor highly restricted to T-lineage cells [38]. Bcl11b is induced in DN2 cells, coinciding with the commitment to the T-cell fate [39]. Its expression is blocked by IL-7 and induced by TCF-1 and Notch signaling [40]. Bcl11b facilitates the expansion of mature CD8 cells and the differentiation of regulatory T cells [41, 42 ]. In thymocyte development, Bcl11b is required for $\alpha \beta$ T-cell survival [43, 44] and its absence causes defective commitment of T-cell precursors, which retain myeloid and NK cell precursor properties (expression of Il2rb and Nfil3), and also express stem/progenitorassociated regulatory genes, such as Flt3 [ 40, 45, 46]. Bcl11b induction marks the downregulation of Kit, the strong upregulation of the genes encoding the CD3 cluster, Thy1 and Rag1 genes, and the rise in Ptcra expression that peaks before $\beta$-selection [ 47 , $48]$.

\section{Regulation of $\mathrm{T}$ cell commitment by transcription factors not restricted to the T-cell lineage}

\section{E proteins and Id repressors}

Members of the E protein family of basic helix-loop-helix transcription factors dimerize to bind the DNA sequence CANNTG (in which $\mathrm{N}$ denotes any nucleotide) and control a variety of developmental processes in vertebrates. In T cell development, E2A (E47 and E12) and HEB (HEBAlt and HEBCan) proteins function mainly as heterodimers. Besides regulating Gata3 expression and IL7R signaling, E2A and HEB are crucial during early T cell development, as they regulate the expression of Rag, Ptcra and Notch1, therefore enforcing the $\beta$-selection checkpoint [49]. These proteins also implement a proliferative checkpoint in thymocyte development, and lack of E2A or HEB induces premature hyperproliferation of DN3 cells [ 50, 51 ]. Also in $\beta$-selection, E47 is required for efficient allelic exclusion of the TCR $\beta$ chain [52]. Once thymocytes reach the DP stage, E2A and HEB proteins are upregulated and block further development until a positive-selection signal is received [53].

Id factors are helix-loop-helix proteins that antagonize E protein function during $\mathrm{T}$ cell development by dimerizing with them. There are four mammalian Id factors, Id1, Id2, Id3 and Id4 [54]. Id1-deficient thymocytes present a severe blockade at the DN1 stage of T cell development [55]. When activated physiologically by the pre-TCR, Id3 suppresses E2A activity transiently [54, 56 ], but its forced overexpression promotes NK cell development at the expense of T cells [57]. During positive selection, inhibition of E proteins by Id factors is critical for thymocytes to proceed to the SP stage.

\section{ETS family}

All ETS (E-twenty-six) family members share a helix-turn-helix DNA-binding domain that binds to DNA sites with a central GGA sequence. Some members of this family have their expression and function regulated during T cell development. For instance, ETS 1 is upregulated at the DN3 stage and promotes allelic exclusion of the TCR $\beta$ gene [ 58, 59], SPIB is induced only at the DN3 stage to arrest the cell cycle during the $\beta$-selection checkpoint [60], but PU.1, which is needed for the generation of precursors with the ability to migrate to the thymus, has to be completely downmodulated at the DN3 stage to promote T cell development as it plays a dominant role to direct myeloid fates. PU.1 specifically inhibits ETS1 and SPIB expression in thymocytes and, consequently, their induction depends on the downregulation of PU.1 [61].

\section{Runx factors}

The three mammalian Runt-related transcription factors (Runx), although not T cell-specific in their expression or function [62], are expressed in thymocytes and function throughout $\mathrm{T}$ cell development. Runx proteins promote DN thymocyte differentiation to DP cells [63]. Runx protein complexes include the non DNA-binding partner core-binding factor $\beta$ (Cbf $\beta)$. A hypomorphic mutation of $\mathrm{Cbf} \beta$ caused the blockade of different consecutive steps within the DN population of thymocytes [64], and deficiency of Runx1 (also known as AML1) in bone marrow progenitors causes a blockade of thymocyte development at the DN2 to DN3 transition $[65,66]$. Runx proteins also control expression of CD8 in the DN-to-DP transition, as well as the selection and maturation of $\mathrm{CD} 8^{+} \mathrm{SP}$ cells $[63,67]$. 


\section{Ikaros family}

Ikaros is the founding member of a family of zinc fingers transcription factors required for the normal development of lymphocytes and other lineages of blood cells. Ikaros itself is essential for the development of B cell and fetal $\mathrm{T}$ cells, and its target genes include many of the pre-TCR components (Cd3d, Ptcra), the Rag locus, Cd8a and the transcription factor Myc [68]. Lack of Ikaros causes thymocytes to transit to the DP stage in a pre-TCR-independent manner, but also gives rise to transformed cells that do require preTCR or TCR signaling [69].

c-Myc

The basic region/helix-loop-helix/leucine zipper transcription factor c-Myc has been described to have different non-redundant functions in thymocyte development. c-Myc expression is induced by pre-TCR signaling, and cellular proliferation and growth during this checkpoint is regulated by c-Myc [70, 71 ]. c-Myc provides a paradigm of the pleiotropic nature of pre-TCR signals, since c-Myc deficient thymocytes not only undergo TCR rearrangements, but $\beta$-selected c-Myc-deficient cells have increased survival [71].

\section{NF- $\kappa B$ proteins}

Transcription factors with a Rel-like domain comprise the nuclear factor kappa-light-chain-enhancer of activated B cells (NF- $\mathrm{kB}$ ) and nuclear factor of activated T cells (NFAT) proteins. NF- $\mathrm{KB}$ transcription factors act as homo or heterodimer combinations from five distinct gene products (p50 and its precursor p105, p52 and its precursor p100, c-Rel, RelA or p65, and RelB) [72, 73 ]. NF-kB activation by the canonical pathway requires the proteolytic degradation of inhibitory proteins (inhibitors of NF- $\kappa B$, I $\kappa B$ ) that

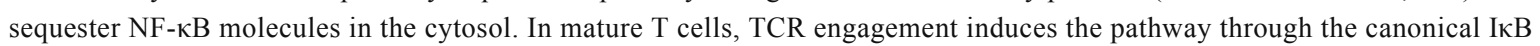
kinase (IKK) complex (made of IKK $\alpha, \beta$ and $\gamma$ proteins) [ 72]. The activated IKK complex phosphorylates IKB, which is subsequently ubiquinitated and degraded by the proteasome, thus releasing NF- $\kappa \mathrm{B}$ to translocate to the nucleus and induce genes that promote differentiation, expansion and survival of T cells. In thymocytes, nuclear NF- $\mathrm{KB}$ activity is markedly increased in DN3 cells and then downregulated in their transition to DP thymocytes [74]. Pre-TCR-induced NF- $\kappa$ B activation promotes thymocyte survival, proliferation and differentiation [74-76]. Regulation of the expression on the Bcl-2 homolog A1 (Bcl2a1) by NF- $\mathrm{B}$ mediates the crucial prosurvival role of the canonical NF- $\kappa B$ pathway downstream the pre-TCR [ 75, 77]. NF- $\kappa \mathrm{B}$ also plays cellintrinsic and cell-extrinsic roles during positive and negative selection of DP thymocytes, in the differentiation of central regulatory $\mathrm{T}$ cells within the thymus, and in $\gamma \delta \mathrm{T}$ cell differentiation [73].

\section{NFAT proteins}

Nuclear factor of activated T cells (NFAT) proteins include four NFATc members (NFATc1-4) and NFAT5. NFATc transcription factors are regulated by the calcium and calmodulin-dependent serine/threonine phosphatase calcineurin, which is activated by an increase of the cytosolic concentration of calcium [ 78, 79]. Activated calcineurin directly binds to and dephosphorylates NFATc transcription factors located in the cytoplasm, inducing their translocation into the nucleus for binding and inducing their target genes. NFATc proteins perform different roles in T lymphocyte development, differentiation, proliferation and survival [78, 79] and for instance NFATc1/ $\alpha$ A is the only NFATc isoform supporting antigen-mediated proliferation and protecting lymphocytes against rapid activation-induced cell death [ 80 ]. Calcineurin and some NFATc proteins are activated downstream both pre-TCR and TCR $\alpha \beta$ signaling pathways $[75,79,81,82]$. As described later in more detail, lack of calcineurin A $\beta$ or B1 subunits [ 83, 84] and lack of NFATc1 (also named NFAT2) or NFATc3 (also named NFAT4) [85-89] causes defects in early thymocyte development, with a partial blockade at the DN3 stage. Remarkable, while the experimental approaches for addressing the role of NFATc3 use the viable Nfatc3-deficient mice as well as conditional early thymocyte (Lck-CRE) induced deletion of this gene [ 86 , 89 ], work with NFATc1 was done using the complementation of RAG blastocyst chimeras with Nfatc1-deficient embryonic stem cells $[85,87]$ or by retroviral transduction in a model cell line [89]. The calcineurin/NFATc pathway also regulates positive selection. Deletion of calcineurin A $\beta$ or B1 subunits, or overexpression of an active form of calcineurin A, revealed that this phosphatase promotes positive selection of DP thymocytes [83, 84, 90 ]. Similarly, chimeric mice deficient for NFATc3 in lymphocytes, the NFATc family member that is predominantly expressed in the thymus [91], have increased apoptosis of DP thymocytes and reduced expression of Bcl2 [86]. Quite strikingly, early deletion of Nfatc1 in thymocyte development revealed that NFATc1 also plays a calcineurin-independent and prosurvival role downstream IL-7R activation [92 ].

NFAT5 is a calcineurin-independent Rel-like protein initially described as an osmoresponsive transcription factor [93, 94]. NFAT5 also regulates different osmostress-independent functions such as the transcription response of macrophages to Toll-like receptor activation by pathogens [95]. In the thymus, NFAT5 expression is upregulated downstream the pre-TCR in an IKK $\beta$-dependent manner [96]. Conditional deletion of NFAT5 in early thymocyte development showed that NFAT5 facilitates thymocyte survival and $\beta$-chain allelic exclusion downstream the pre-TCR, but is not required for the positive or negative selection of DP thymocytes induced by the mature TCR [96]. NFAT5 facilitates the transition from DN3 thymocytes to DP cells in the absence of a detectable osmostress response, an effect that could be associated with enhanced expression of Bcl-2 and A1 (Bcl2a1) and attenuated p53/Noxa axis.

\section{Other transcription factors not restricted to the T-cell lineage}

Besides the factors described above, the factors retinoic acid-related orphan receptor gamma $\mathrm{t}(\mathrm{ROR} \gamma \mathrm{t}$ ) and myeloblastosis viral oncogene homolog $(\mathrm{Myb})$, which have been more extensively characterized in mature $\mathrm{T}$ lymphocytes and other cells, also regulate thymocyte development. ROR $\gamma t$ is the thymus-specific isoform of ROR $\gamma$ that is induced specifically during $\beta$-selection [97]. Mice 
deficient for this factor have a defective DN-to-DP transition in thymocyte development [98 ]. Conditional deletion of Myb causes a developmental blockade at the DN3 stage, with reduced V(D)J recombination in the TCR $\beta$ locus [99, 100 ]. Rag and Ptcra are cMyb target genes that reflect the relevance of this transcription factor for the commitment of thymocytes to the $\alpha \beta$ lineage [ 101 , $102]$.

\section{Apoptosis in $\mathrm{T}$ cell development}

The regulation of cell survival and death during T cell development contributes significantly to the generation of functional mature $\mathrm{T}$ cells. There are many checkpoints along $\mathrm{T}$ cell development that rely on the fine-tuning of cell death and survival to control progression through the next differentiation step. Thymocytes have to be able to respond to cytokines released from thymic stromal cells in order to avoid cell death and, in addition, they have to express a functional pre-TCR or TCR to survive and be properly selected. It is clear that during these processes, the anti-apoptotic and pro-apoptotic signals are of great importance. For instance, DP thymocytes undergo positive or negative selection after rearranging its TCR $\alpha$ chain [103, 104]. Cells bearing a rearranged mature TCR of high affinity for self-antigens are subjected to negative selection to prevent the existence of autoreactive T lymphocytes, and those bearing a TCR with intermediate affinity are positively selected. But nevertheless, the majority of DP thymocytes does not express a successfully rearranged mature TCR and undergoes death by neglect [103, 104$]$.

There are two major apoptotic pathways, the extrinsic pathway controlled by death receptors of the tumor necrosis factor receptor superfamily, and the intrinsic pathway mainly controlled by pro-apoptotic Bcl-2 family members. Although both pathways have been shown to act during thymocyte development, the intrinsic pathway has been found to be more relevant in many steps of thymocyte differentiation [105].

\section{The intrinsic apoptotic pathway and its effect in thymocyte development}

The intrinsic apoptotic pathway is activated by stimuli as genomic toxicity and cytokine withdrawal. Intrinsic death signals converge at the outer membrane of the mitochondria to disrupt its integrity and then activate downstream apoptotic pathways. Bcl-2 family members are the major mediators of the intrinsic apoptotic pathway. This family comprises both death agonists and antagonists whose activity or expression is tightly controlled at different steps of thymocyte development [105]. Various examples of transcription factors that control thymocyte survival by regulating the expression of different Bcl-2 proteins have been mentioned in the previous section. Bcl-2 family proteins share structural homology within $\alpha$-helical segments denoted as Bcl-2 homology (BH) domains numbered BH1-4 [106-108].

There are three groups of Bcl-2 proteins defined by their structural motifs. Anti-apoptotic family members, Bcl-2, Bcl- $\mathrm{x}_{\mathrm{L}}$, Mcl-1 and Bcl-2A1 (A1) possess all 4 BH domains. They all inhibit the pro-apoptotic Bcl-2 family members through BH domain interactions. Bcl-2 has a prominent prosurvival role during early thymocyte development downstream the IL-7 receptor [109, 110]. IL-7 signaling also upregulates the expression of Mcl-1, which is then required for DN thymocyte survival [ 111]. The expression of Bcl$\mathrm{x}_{\mathrm{L}}$, the main isoform of Bcl-x, is tightly regulated during thymocyte development at the double-positive stage [112, 113] and plays a non-redundant role in DP cell survival $[113,114]$. Bcl-2A1 (A1) is a transcriptional target of the pre-TCR expressed in an NF- $\mathrm{B}$ - and NFAT5-dependent manner to facilitate DN3 thymocyte survival [76, 96].

The multi-domain pro-apoptotic members Bax and Bak possess the BH1-3 domains. They are the main executers of the intrinsic pro -apoptotic pathway [115-117]. Their function is explained by their capacity to form supermolecular openings in the outer membrane of the mitochondria, leading to the loss of mitochondrial integrity with the release of pro-apoptotic factors as cytochrome C. Cytosolic cysteine proteases called caspases are subsequently activated to induce the downstream steps of cell death. The transcriptional repressor growth factor-independent 1 (Gfi-1) inhibits the expression of Bax and, in addition to its role facilitating the DN2 to DN3 transition [118, 119], the ratio of Gfi-1 to its target Pim-1 determines that pre-T-cells pass the 'DN3a' to 'DN3b' transition correctly during $\beta$-selection $[120,121]$.

A subset of pro-apoptotic proteins that includes Bid, Bad, Bim, Bik, Bmf, Noxa and Puma, possesses only the BH3 domain. Instead of being direct executioners of cell death, they act as facilitators of the function of Bax and Bak, or by blocking the anti-apoptotic effect of prosurvival Bcl-2 family members [122, 123]. Different cell death stimuli activate or induce the expression of different BH-3 only proteins. p53-regulated apoptosis is activated during V(D)J recombination (as it involves double-strand DNA breaks) and is suppressed when a correct TCR $\beta$ rearrangement and a functional pre-TCR signaling are achieved [124-127]. In the absence of survival signals, p53 induces death by activation of pro-apoptotic molecules such as Noxa, Puma and Bid [128-131]. As discussed in a previous section, the pre-TCR can promote survival of DN thymocytes through transcriptional induction of anti-apoptotic Bcl2 proteins and attenuation of the p53/Noxa axis $[75,77,96]$.

\section{IL-7 and Notch signaling drive early thymocyte development before pre-TCR expression}

Interleukin-7 signaling is necessary for early T cell development by promoting cellular expansion and survival [ 8 ]. IL-7 induces the expression of B cell leukemia/lymphoma 2 (Bcl-2) and myeloid cell leukemia sequence 1 (Mcl-1), which are essential prosurvival factors [ 109-111]. During T cell development, the IL-7 receptor (IL-7R) is expressed on DN2 cells, pre- $\beta$-selected DN3 cells and also in SP cells $[132,133]$. The IL-7R signals via the phosphatidylinositol-3-kinase (PI3K)/Akt pathway, and also via the Janus kinases (JAK) JAK1 and JAK3 and their target signal transducer and activator of transcription 5 (STAT5) [ 134]. STAT5 cooperates 
with NFATc1, which is activated by an alternative JAK3-dependent pathway to guide thymocyte survival and development downstream the IL-7R [92 ]. Subsequent steps in thymocyte development marked by pre-TCR function are favored by the downregulation of IL-7R signaling and cell-cycle-activating genes by E proteins (E2A and HEB) [20, 51].

Notch signaling is also critical for $\mathrm{T}$ cell development and represents one of the best-studied T-cell lineage positive regulators. Notch is a transmembrane receptor involved in direct cell-cell signaling by interacting with a transmembrane ligand of the Delta/Jagged family in neighboring cells. Mammals possess four Notch receptors (Notch 1-4) and five ligands: two Serrate-like ligands called Jagged-1 and Jagged-2, expressed by the bone marrow stroma, and three Delta-like (DL) ligands called DL1, DL3 and DL4. In accordance with the importance of Notch signaling in early stages of T cell development [135], DL1 and DL4 are expressed by cTECs, being DL4 the predominant Notch ligand in the thymus [136, 137].

The extracellular portion of the Notch receptor consists of ligand-binding epidermal growth factor (EGF)-like repeats and Notch/LIN-12 repeats that prevent ligand-independent signaling [138]. Receptor-ligand interaction leads to the proteolytic cleavage of Notch that releases its intracellular domain. The intracellular Notch domain (ICN) translocates to the nucleus to bind the transcription factor recombination signal binding protein for immunoglobulin $\mathrm{J} \kappa(\mathrm{RBPJ} \kappa)$, displacing the Groucho co-repressor and recruiting co-activators such as Mastermind-like proteins (MAML). Several genes are directly activated by the Notch/RBPJא complex during thymocyte development: Ptcra (encoding the pT $\alpha$ ) [102], the transcription factor hairy, enhancer of split 1 (Hes1), Deltex1 [135] and Tcf7 [32], as well as a number of receptors and transcription regulators, including Cd25, Il7r, Tcf12, Runx1, Gfi1, Ets1, Gata3, Rag1.

Among all four Notch receptors, Notch1 plays an indispensable role during T cell development, particularly in the T versus B lineage choice [139]. Mice deficient in Notch1 in hematopoietic stem cells (HSCs) display an arrest at the DN1 stage of T cell development and generate B cells intrathymically [7].

Notch also influences the pre-TCR, since it is necessary for TCR $\beta$ rearrangements [140] and also for the transcription of the preTCR $\alpha$-chain $(\mathrm{pT} \alpha)$ [102]. Notch facilitates the $\alpha \beta$ lineage choice at the point of emergence and divergence between the $\alpha \beta$ and $\gamma \delta$ lineages in DN3 cells [141]. Transition through the $\beta$-selection checkpoint requires cooperative signaling of Notch and the preTCR, whereby Notch ensures survival by regulating the metabolism of glucose, an essential nutrient required for cellular energy and biosynthesis [14].

Thymocytes become independent from Notch at the immature single-positive (ISP) stage, in the DN-to-DP transition, and Notch signaling is dispensable in subsequent stages of thymocyte differentiation [142]. Notch1 is poorly expressed in DP cells and conditional inactivation of Notch 1 after $\beta$-selection does not result in any developmental defects [143, 144].

\section{Early lineage plasticity in $\mathrm{T}$ cell development}

The DN1 population has the capacity to generate multiple lineages (B cells, NK cells, DCs and myeloid cells) and already expresses, albeit at low levels, certain T cell receptors (CD44, CD24, Thy-1). Other receptors, such as IL-7R $\alpha$, CD25, CD3 chains, and the TCR signaling components ZAP70, LAT and Lck, are induced when thymocytes differentiate into DN2 cells [61]. Based on the expression of Lck and c-kit, DN2 cells can be further subdivided in two subpopulations with different lineage potential: DN2a $\left(\mathrm{Lck}^{-} \mathrm{c}-\mathrm{kit}^{\mathrm{hi}} \mathrm{CD} 25^{+}\right)$that can give rise to myeloid, NK cells and DCs; and DN2b $\left(\mathrm{Lck}^{+} \mathrm{c}-\mathrm{kit}^{\mathrm{int}} \mathrm{CD} 25^{+}\right)$that become T-lineage restricted [39]. Development from early T-cell lineage DN1 progenitors to DN3 cells is independent of the TCR. DN1 and DN2 cells proliferate extensively while acquiring their first T cell characteristics. Finally, by the DN3 stage, T-cell identity is set, c-kit and CD44 are downmodulated, cells stop proliferating, and the TCR $\beta$ gene is rearranged and expressed as part of the pre-TCR. DN3 thymocytes that succeed in making in-frame TCR $\beta$ gene rearrangements become larger cells (referred to as DN3b, and also known as late DN3 cells, DN3L) expressing low levels of CD27, which distinguishes them from $\mathrm{CD} 27^{+} \mathrm{DN} 3$ cells that were not yet selected (referred to as DN3a, also known as early DN3 cells, DN3E) [145, 146].

Regulation of lineage plasticity during early thymocyte development also exhibits strong transcriptional control (Fig. 1; Table 2). In this regard, Id2 induces NK cell development [19], GATA-2 is involved in the generation of megakaryocytes and mast cells [147], The CAAT-enhancer binding protein alpha (C/EBP $\alpha)$ induces myeloid development [148] and PU.1 induces myeloid and B cell development $[148,149]$. Factors that facilitate lineage plasticity must be silenced in order to establish the $\mathrm{T}$ cell fate. This requires, among others, signaling and transcriptional activation of target genes by Notch1 after its interaction with its Delta-like ligands expressed on the thymic stroma. However, Notch1 is necessary but not sufficient for T cell commitment, and other transcription factors cooperate with it in the T cell specification of early precursors. These include GATA-3, TCF-1, E proteins, Runx1, Ikaros family members, the proto-oncogene c-Myb and the transcriptional repressor Gfi-1 [61] (Fig. 1; Tables 1, 2). Moreover, other transcription factors are specifically induced at the DN2 stage to reinforce the setting of T-cell identity, like the E protein HEBAlt, which acts by preventing myeloid development [150] and Bcl11b (B-cell lymphoma 11b) that blocks NK cell development [45].

\section{Fig. 1}

Expression of transcription factors promoting early $\mathrm{T}$ cell development 


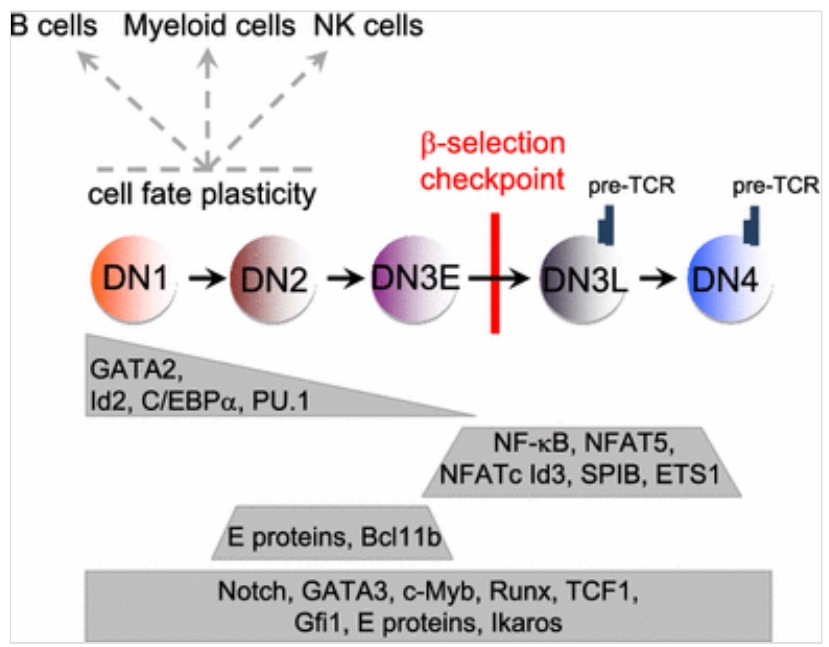

Table 2

\begin{tabular}{|l|l|}
\hline Relevant events before pre-TCR expression & Signaling pathways/proteins \\
\hline Cell-cycle arrest & E proteins, SPIB, p27 $7^{\text {Kip1 }, ~ p 21^{\text {wafl }}, \text { ROR } \gamma \mathrm{t}}$ \\
\hline TCR $\beta$ rearrangements & Rag recombinases, Notch, c-Myb \\
\hline Survival & Notch, IL-7R \\
\hline Inhibition of non-T fates & Downregulation of PU.1, Id2, GATA-2, CEBP $\alpha$ \\
\hline Expression of RAG & Upregulation of Bcl11b, HEBalt, Notch \\
\hline
\end{tabular}

\section{Rearrangement of the TCR $\beta$ gene}

The accomplishment of DNA rearrangements that generate functional TCR proteins is indispensable for the survival and progression of T-cell precursors. The genomic locus of each TCR contains many copies of V, D, J segments whose combination generates the great diversity of TCR specificities that can be found in one individual organism and is largely responsible for the ability of the immune system to respond to different antigens [151].

The joining of rearranged $\mathrm{V}, \mathrm{D}$, and $\mathrm{J}$ segments is imprecise, and two-thirds of the fused DNA segments fail to maintain the translational reading frame, generating nonfunctional TCR- $\beta$ proteins [152]. As a result, almost half of the DN thymocytes attempting to rearrange their TCR- $\beta$ genes fail on both alleles. Accumulation of these dead-end cells is prevented by $\beta$-selection. Therefore, implicit in the process of TCR $\beta$ V(D)J recombination is the existence of a developmental checkpoint, the so-called " $\beta$ selection checkpoint" [ 145 ], to ensure that only those cells that have productively rearranged their TCR $\beta$ loci can undergo further differentiation, whereas those that fail, suffer cell death [153].

$\mathrm{V}(\mathrm{D}) \mathrm{J}$ recombination for the TCR $\beta$ loci is initiated by the RAG-1 and RAG-2 endonucleases, which cleave gene segments producing double-strand breaks at specific recognition sequences. Broken ends are then processed and joined by factors generally involved in repair of non-homologous end joining DNA breaks [154]. Expression of Rag genes is induced by transcriptional regulators including GATA-3, Ikaros, C/EBP $\alpha$, HEB/E2A and c-Myb [101] (Table 2). Once DN3 cells receive a pre-TCR signal, Rag genes are downregulated, due in part to the upregulation of Id3, which blocks HEB/E2A activity [56].

The assembly and expression of an antigen receptor chain from one allele inhibits further V(D)J recombination on the other allele. This is termed "allelic exclusion", and is defined as the surface expression of BCR or TCR chains from a single allelic copy, and is maintained by feedback negative regulation [155]. Allelic exclusion determines that each T cell will only express one TCR specificity, an important point for facilitating central tolerance of self-reactive lymphocytes and avoiding autoimmunity.

Nonetheless, a small percentage (1-3\%) of TCR $\beta$ loci escape allelic exclusion, which results in some lymphocytes exhibiting polyspecific antigen recognition due to two different TCR being expressed in the same cell [155]. As discussed below, the mechanisms that control allelic exclusion in the TCR $\beta$ locus are poorly characterized but some transcription factors are known to be involved.

\section{Thymocyte $\beta$-selection through different pre-TCR-induced outcomes}

Pre-TCR signaling has the ability to regulate diverse biological outcomes, each one of them appearing to be, for the most part, functionally unrelated to the rest $[77,156-158]$. Signaling initiation and functional outcomes distinguish the pre-TCR from the 
mature $\gamma \delta$ TCR and $\alpha \beta$ TCR $[159,160]$. The pre-TCR rescues cells from apoptosis, restarts the cell cycle, upregulates CD4 and CD8 expression, downregulates CD25 expression, ends TCR $\beta$ rearrangements by imposing allelic exclusion, and initiates TCR $\alpha$ expression. These unique functions of the pre-TCR control the $\beta$-selection checkpoint in thymocyte development ensuring that only thymocytes with productive in-frame TCR $\beta$ rearrangements will go into the processes of positive and negative selection, leading to the TCR repertoire and defining antigen specificity.

The discovery of the pre-TCR was driven by the realization that the rearrangement of the gene encoding TCR $\beta$ takes place before the TCR $\alpha$ gene is rearranged $[11,161]$. Indeed, TCR- $\beta$ chains drive the differentiation of DN to DP thymocytes in the absence of TCR- $\alpha$ chains [ $162-165$ ]. The pre-TCR is a multisubunit complex that includes a recombined TCR $\beta$ chain bound to the invariant pre-TCR $\alpha$ chain $(\mathrm{pT} \alpha)$ and CD3 signaling molecules $[12,13]$. The pre-TCR is clustered in glycolipid-enriched microdomains of the plasma membrane [159] and transduces weak signals that favor the commitment of the immature DN cells towards the $\alpha \beta$ lineage and not the $\gamma \delta$ one $[153,166,167]$. The pre-TCR presents lower levels of surface expression than the mature TCR, and this was proposed to be due, at least in part, to its nature of disulfide-linked heterodimeric proteins, which are very often degraded in the endoplasmic reticulum [157]. Another explanation proposed for its low level of surface expression is the fact that its constitutive signaling would induce the rapid internalization and degradation of the pre-TCR in lysosomes in a proteasome- and ubiquitin-ligase-dependent manner [168].

Expression of the Ptcra gene encoding the pre-TCR-specific alpha chain is upregulated at the DN2 stage by the transcription regulators c-Myb, E proteins (E2A-HEB heterodimers), and the Notch-dependent transcription factor RBPJк [102, 169] (Table 3 ). The mRNA of Ptcra increases along the differentiation of DN cells, and is fully extinguished in DP cells after the rearrangement of the TCR $\alpha$ gene and the membrane expression of a mature TCR $\alpha \beta[170]$.

Table 3

\begin{tabular}{|l|l|}
\hline Pre-TCR complex molecules & Transcription factors that induce pre-TCR (complex) gene expression \\
\hline TCR $\beta$ promoters and enhancers & Ets1, Runx 1, Notch \\
\hline $\mathrm{pTa}$ & Notch, E proteins, c-Myb, Ikaros, Egr1 \\
\hline $\mathrm{CD} 3$ molecules & GATA-3, TCF-1, Ikaros \\
\hline
\end{tabular}

Signaling by the pre-TCR is ligand-independent and does not require recognition of MHC-presented antigens, in clear contrast to the mature TCR $[159,171]$. The signaling ability of the pre-TCR is controlled by both its extracellular immunoglobulin-like domain, which facilitates the oligomerization of the pre-TCR complex [172], and also its cytoplasmic tail, which is required for downstream signal transduction [173]. Signals from the pre-TCR synergize with signals that activate the Notch pathway in DN3 thymocytes to induce the transition of DN thymocytes to DP cells [174]. In addition, the chemokine receptor CXCR4 was described to associate with the pre-TCR acting as a costimulatory molecule to control survival during $\beta$-selection in a PI3K-dependent manner $[175,176]$. The Wnt signaling pathway contributes to the expansion and differentiation of thymocytes beyond the $\beta$-selection checkpoint. LEF1-deficient mice and mice expressing mutant forms of TCF-1 present an early arrest in T cell development [ 177 , 178 ]. $\beta$-catenin plays a crucial role in activating these transcription factors as pre-TCR-defective DN cells overexpressing $\beta$-catenin proceed to the DP stage of T cell development [36]. Pre-TCR signals stabilize $\beta$-catenin in DN thymocytes during $\beta$-selection through Erk activity, which in turn mediates sustained expression of Egr genes [37].

Despite its lack of conservation between humans and mice, the cytoplasmic tail of the pre-TCR, and particularly a proline-rich motif in the tail, is required for its function [173, 179]. Targeting of proximal components of the pre-TCR signaling cascade have shown that the SRC-family kinase $556^{\mathrm{Lck}}$ (Lck), $\zeta$-associated protein of $70 \mathrm{kDa}$ (ZAP70), linker for activating T cells (LAT), and SH2 domain-containing leukocyte-specific phosphoprotein of $76 \mathrm{kDa}$ (SLP-76) are early signaling components engaged by the pre-TCR [158, 180 ]. Pre-TCR signals (Fig. 2) are transduced through the immunoreceptor tyrosine-based activation motifs (ITAMs) located in the cytoplasmic tails of CD3 chains, which become phosphorylated by the Src-family protein kinases Lck and Fyn [181, 182 ]. ZAP-70 and Syk are then recruited to the CD3 tail of the pre-TCR complex [183-185] and activate adaptor proteins as LAT, SLP-76 and Vav that initiate three signaling pathways through the activation of PI3K, PLC $\gamma$ and Ras [77, 156, 157] (Fig. 2). Apart from the signaling pathways activated by the pre-TCR, this complex also blocks death signals. These survival signals block the DNA damage-responsive p53 pathway and function in a manner independent of the adaptor FADD (Fas-associated death domain protein) $[77,156]$.

\section{Fig. 2}

Diagram summarizing the main signaling pathways downstream the pre-TCR. A functional TCR $\beta$ chain, the invariant $\mathrm{pT} \alpha$ and CD3 components assemble into the pre-TCR receptor complex. Proximal signaling involves activation of Lck and Fyn, ZAP-70, LAT, Vav and SLP-76, which initiate distal signaling pathways. The PI3K pathway, shown in green, inhibits apoptosis and cell-cycle arrest. The PLC $\gamma$ pathway, shown in purple, promotes proliferation, differentiation, survival and allelic exclusion. NFAT5 is shown downstream of IKK and NF-KB. The Ras/Raf pathway, shown in blue, promotes proliferation and differentiation of DN3 cells. Pre-TCR signaling also inhibits p53, which would otherwise cause cell-cycle arrest and induce apoptosis in cells that have not produced successful TCR $\beta$ rearrangements. For members of the NFATc family of transcription factors, although they are differentially involved in the control of 
cellular proliferation and survival, this diagram reflects the reported function for particular NFATc proteins (NFATc1 and NFATc3) facilitating pre-TCR-induced thymocyte differentiation

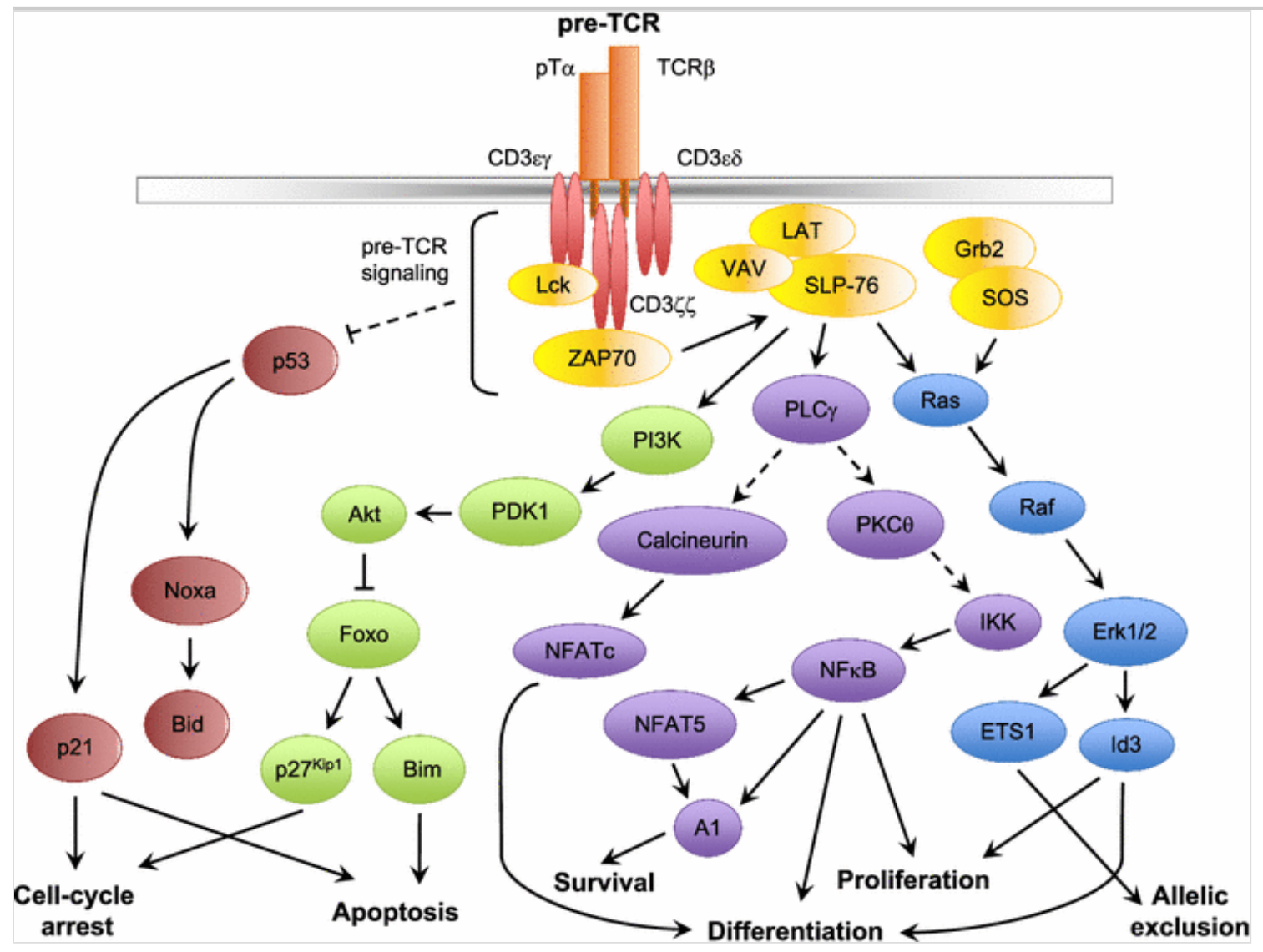

While the hierarchy of molecules that assemble the different signaling cascades of the pre-TCR is quite established, knowledge on the target genes that respond to these inputs and the specific mechanisms that regulate their expression is more limited (Fig. 2; Table 4). Completing the puzzle of transcription factors that lay beneath the different signaling branches of the pre-TCR and learning which genes they regulate would provide a complete picture of the way this receptor controls the commitment of $\alpha \beta-$ lineage thymocytes. The next sections summarize what is known about different signaling branches of the pre-TCR and their specialization in activating different transcription factors to drive its multiple functions. As discussed previously, transcription factors known to be involved in pre-TCR expression or function can also work in other, pre-TCR-independent, roles in thymocyte development or mature $\mathrm{T}$ lymphocytes.

\section{Table 4}

Pre-TCR outcomes and signaling pathways

Proliferation

Allelic exclusion

Differentiation

PI3K pathway

PLCg/DAG/PKC pathway

PLCg/IP3 pathway

Ras/MAPK pathway

\section{Proteins activated downstream}

Pathways that cooperate or synergize with the pre-TCR: Notch, CXCR4, Wnt

Transcription factors downstream pre-TCR: NK-kB, ETS1, NFAT5

Prosurvival outcomes promoted by the pre-TCR: expression of anti-apoptotic A1, suppression of p53, inhibition of FOXO

TCF-1, NF-kB, c-Myb, Id3, Egr3, Cyclin D3. Negative regulators of proliferation include ROR $\gamma \mathrm{t}$ and $\mathrm{E}$ proteins

Ets1, E2A (E47), NFAT5

NK-kB, NFATc (NFATc1 and NFATc3), Runx1, TCF-1, Egr

Inhibits FOXO, Bim, p27 $7^{\mathrm{Kip} 1}$

NF- $\kappa B$, NFAT5, A1

Calcineurin/NFATc pathway

ETS1, Egr proteins, Id3, inhibition of ROR $\gamma \mathrm{t}$ 


\section{PI3K pathway: activation of Akt-induced survival}

Upon activation of phosphatidylinositol-4,5-bisphosphate 3-kinase (PI3K), various 3-phosphorylated phosphoinositides (PtdIns3P, PtdIns(3,4)P2, PtdIns(3,5)P2, and PtdIns(3,4,5)P3) are produced in the membrane [186]. The different phosphoinositides allow the recruitment to the cellular membrane of various signaling proteins containing phosphoinositide-binding domains, such as PX domains, pleckstrin homology domains (PH domains), and FYVE domains. Protein kinases PDK1 (phosphoinositide-dependent kinase-1) and AKT contain a PH domain specific for PtdIns(3,4,5)P3 and PtdIns(3,4)P2, which causes them to translocate to the plasma membrane upon PI3K activation. Colocalization of activated PDK1 and AKT enables PDK1 to phosphorylate AKT, leading to its partial activation. AKT activation is of central relevance in pre-TCR signaling since it maintains survival of DN3 cells through phosphorylation-dependent inhibition of Forkhead box O (FOXO) transcription factors, which promote cell-cycle arrest and apoptosis $[187,188]$. The increased susceptibility of AKT-deficient immature thymocytes to undergo apoptosis is probably due to both dysregulation of the expression of Bcl-2 family members as Bim but also impaired glucose metabolism [131, 187]. Notably, during $\beta$-selection, Notch also acts via AKT promoting survival independently of pre-TCR signals [14]. Apart from AKT, PDK1 also phosphorylates the ribosomal subunit kinases S6K and RSK, which lack a PH domain and are required downstream of Notch for optimal pre-T cell growth and proliferative expansion $[186,189]$.

\section{PLCY pathway: activation of NFAT, NF- $\kappa B$ and the MAPK pathways to induce differentiation, survival and proliferation}

Phosphorylation of phospholipase C $\gamma$ (PLC $\gamma$ ) activates it to yield diacylglycerol (DAG) and inositol 1,4,5-trisphosphate (IP3) from the hydrolysis of $\mathrm{PIP}_{2}(\operatorname{PtdIns}(4,5) \mathrm{P} 2)$. Different signaling pathways derive from these two molecules.

IP3 causes an efflux of cytosolic calcium $\left(\mathrm{Ca}^{2+}\right)$ from endoplasmic reticulum stores, and the elevated levels of intracellular $\mathrm{Ca}^{2+}$ result in calmodulin saturation and the direct activation of the phosphatase calcineurin [190]. Calcineurin is composed of a catalytic A subunit and a regulatory B subunit. Activated calcineurin directly binds and dephosphorylates cytosolic NFATc transcription factors, which then translocate into the nucleus to transactivate their target genes [ 78, 79]. Mice lacking the major calcineurin catalytic isoform expressed in lymphocytes, $\mathrm{CnA} \beta$, or removal of $\mathrm{CnB} 1$ function specifically in $\mathrm{T}$ cells, present a partial block at the DN3 stage of thymocyte development [ 83, 84]. Accordingly, it was reported that NFATc proteins promote differentiation of DN3 cells, since lack of either NFATc1 or $\mathrm{c} 3$ in thymocytes causes a partial block at the DN3 stage followed by reduced survival of DP thymocytes [36, 85-87]. In support of the notion that the calcineurin/NFATc pathway regulates pre-TCR-induced thymocyte differentiation to DP cells, enforced expression of NFATc1 partially bypasses the need of pre-TCR signaling to induce thymocyte passage through the $\beta$-selection checkpoint and revealed that Id3 is an NFATc target gene $[88,89]$.

DAG activates different forms of the protein kinase C (PKC) family. Particularly relevant for T cells is PKC $\theta$ [ 191, 192 ], which activates the IKK complex and NF- $\mathrm{\kappa B}$ in response to TCR signaling [72]. Indeed, PKC $\theta$ acts as a target of Notch3 signaling to mediate pre-TCR-induced NF- $\kappa \mathrm{B}$ activation [193], which is consistent with the described role of PKC regulating allelic exclusion and differentiation downstream the pre-TCR [194]. As mentioned earlier, NF- $\kappa B$ is an essential regulator of different pre-TCR functions as it promotes differentiation, intensive cellular expansion, and survival of thymocytes that transit from the $\beta$-selection checkpoint to DP cells [74-76]. The prosurvival Bcl-2 family protein A1 is expressed in an NF- $\mathrm{kB}$-dependent manner downstream the pre-TCR. Interestingly, the conventional IKK $\beta / \mathrm{NF}-\kappa \mathrm{B}$ pathway regulates the expression of the transcription factor NFAT5, which in turn, not only binds the promoter region of the A1 gene (Bcl2a1) but also binds the Bcl2 promoter to facilitate their expression in DN cells and support thymocyte survival [96]. Although the pre-TCR marks a window of thymocyte development with reduced Bcl-2 expression, the NFAT5-regulated Bcl-2 expression during the transit of $\beta$-selected thymocytes to DP cells can be interpreted as a means to support a threshold of activity for this prosurvival factor downstream the pre-TCR.

\section{The RAS-mitogen-activated protein kinase (MAPK) pathway: proliferation, differentiation and allelic} exclusion

The Ras-Raf-MEK1/2-Erk1/2 MAP kinase (MAPK) cascade, which is directly activated through SLP-76 and Grb2-SOS is a relevant player downstream the pre-TCR $[195,196]$ to fuel the proliferation and differentiation of $\beta$-selected DN3 thymocytes [77]. Extracellular signal-regulated kinase (Erk) controls the activation of ETS1 and early growth response (Egr) transcription factors [197]. ETS1 is required for thymocyte survival and allelic exclusion downstream of the pre-TCR [59]. The expression of Egr family members Egr1, 2, and 3 correlates with pre-TCR expression and thymocyte development beyond the $\beta$-selection checkpoint, and enforced expression of different Egr factors bypasses the block in development associated with defective pre-TCR function [ 197, 198 ]. However, different Egr family members may have somewhat distinct roles in promoting thymocyte development since there are differences in genes that, such as Rag1, Rag2, Ptcra and Tcra, are modulated by enforced expression of particular Egr factors [197]. Egr1 was shown to be upregulated in $\beta$-selected cells promoting their development to the immature CD8 single-positive stage [199]. This transcription factor acts together with NFATc1 to induce development beyond the $\beta$-selection checkpoint, as they synergistically induce expression of Id3 [88,200, 201 ], a transcriptional repressor that antagonizes the activity of E proteins E12, E47 and HEB and therefore promotes proliferation and progression to the DP stage [56]. Egr3-induced Id protein expression also results in a transient loss of E protein-dependent ROR $\gamma \mathrm{t}$ expression and directly affects ROR $\gamma$ t function blocking the expression of anti-proliferative genes, such as cytoplasmic polyadenylation element binding protein 4 (mCPEB4) [202]. These works lend support to the view that control of proliferation by pre-TCR signals is highly dependent on the activities of the transcription factors ROR $\gamma \mathrm{t}$, Egr3, E12, and E47. Regarding the activity of E47 downstream pre-TCR, although it is clear that it must be antagonized to facilitate proliferation, it is also required to control TCR $\beta$ allelic exclusion [52 ]. 


\section{Blockade of p53-dependent pro-apoptotic and anti-proliferative functions by the pre-TCR}

The response of thymocytes to pre-TCR signaling includes gene rearrangements and proliferation, two processes that are incompatible and must occur sequentially. V(D)J recombination requires exit from the cell cycle [203 ]. Small DN3a cells undergoing TCR $\beta$ rearrangements are quiescent cells, and large DN3b cells represent thymocytes that enter cell cycle after the rearrangements are completed and the pre-TCR is functional. Among other factors, cell-cycle arrest of DN3a cells is regulated by the tumor suppressor p53. p53 induces p2 $1^{\text {wafl }}$ which, in addition to its function as a modulator of cell death and its oncogenic p53independent role in thymic lymphomas [204], acts together with the FOXO-regulated p $27^{\text {kip }}$ to arrest the cell cycle [205, 206]. Reentry into the cell cycle occurs in DN3b cells, promoted by functional pre-TCR signaling. Pre-TCR signaling has also been linked to the inhibition of DNA damage-dependent p53-mediated apoptosis. In the absence of survival signals, an accumulation of p53 induces cell death by activating pro-apoptotic molecules such as Noxa, Puma and Bid, which in turn will activate Bax to translocate to mitochondria and initiate the cascade of caspases that leads to cell death [131]. The apoptotic function of p53 is activated during $\mathrm{V}(\mathrm{D}) \mathrm{J}$ recombination of the TCR $\beta$ locus (as it involves DNA double-strand breaks) and is suppressed if a correct TCR $\beta$ rearrangement is produced $[125,126]$. Indeed, blockade of thymocytes at the DN3 stage observed in mice defective for pre-TCR signaling is prevented when $\mathrm{p} 53$ is deleted $[124,126,207]$. Although it is known that the guanine nucleotide binding protein/GTPase Rho suppresses p53-mediated apoptosis downstream of the pre-TCR [127], the signaling steps that link the preTCR to inhibition of p53 are not fully elucidated. Recent evidence shows that the transcription factor Miz-1 induces the expression of the gene encoding ribosomal protein L22 (RPL22), a negative regulator of p53 translation [208], which is consistent with the role of Miz-1 and RPL22 as prosurvival molecules that antagonize p53 during the $\beta$-selection checkpoint of thymocytes [209$211]$.

Besides the regulators discussed in previous sections, there are some pre-TCR induced proteins that regulate thymocyte function, but whose connection with signaling components of the pre-TCR complex is poorly characterized. For instance, cyclin D3 is upregulated after $\beta$-selection to promote cell-cycle entry, and thymocytes lacking it show defective expansion and are more susceptible to oncogenic transformation [212]. On the anti-proliferative side, the ETS transcription factor SPIB is highly expressed in DN3 cells and restrains their proliferation, but its expression is turned off after $\beta$-selection [60].

\section{Future perspectives}

The pre-TCR controls the $\beta$-selection checkpoint in thymocyte development through a balanced combination of processes the determine cell survival, death, proliferation, and cell-cycle arrest. Transcription plays a main role in these processes, and specific transcription regulators coordinate their function to facilitate the transit of thymocytes through the $\beta$-selection checkpoint.

Despite knowledge accumulated during the last two decades on the identity of the transcription factors that sense the pre-TCR signaling and induce its distinct functional outcomes, the identification of the specific genes they bind and induce is still limited. Resolving gene expression profiles during pre-TCR-regulated thymocyte transitions, and the changes in chromatin architecture and transcription factor dynamics involved, poses a major challenge due to the difficulty of isolating cell subsets or differentiation stages represented in very small numbers. Fortunately, advances in single cell RNA sequencing and novel technologies, such as the recently developed iChIP assay [213,214], a variation of the chromatin immunoprecipitation sequencing, are greatly facilitating the analysis of gene regulation events in limited amounts of cells during development transitions. These techniques, in combination with gene knockouts and genetic tagging for lineage tracking, will likely expand our understanding on how the pre-TCR converts the activation of its different signaling branches into distinct gene expression programs.

\section{Acknowledgments}

Work in CL-R and JA laboratory has been supported by the Ramón y Cajal and I3 Researchers Programs (CL-R), research grants from the Spanish Government (SAF2009-08066, SAF2012-36535 to CL-R; and BFU2008-01070, SAF2011-24268 to JA), Fundació la Marató TV3 (080730, 122530 to CL-R and JA), the Marie Curie International Reintegration Program of the European Union (MCIRG516308 to CL-R), the Spanish Ministry of Health (ISCIII-RETIC RD06/0009-FEDER), and Generalitat de Catalunya (2009SGR601, 2014SGR1153). CL-R is a recipient of the ICREA Acadèmia Award (Generalitat de Catalunya).

\section{References}

1. Rossi SW, Jenkinson WE, Anderson G, Jenkinson EJ (2006) Clonal analysis reveals a common progenitor for thymic cortical and medullary epithelium. Nature 441:988-991

2. Yang Q, Jeremiah Bell J, Bhandoola A (2010) T-cell lineage determination. Immunol Rev 238:12-22

3. Schwarz BA, Bhandoola A (2004) Circulating hematopoietic progenitors with T lineage potential. Nat Immunol 5:953-960

4. Serwold T, Ehrlich LIR, Weissman IL (2009) Reductive isolation from bone marrow and blood implicates common lymphoid progenitors as the major source of thymopoiesis. Blood 113:807-815

5. Lind EF, Prockop SE, Porritt HE, Petrie HT (2001) Mapping precursor movement through the postnatal thymus reveals specific microenvironments supporting defined stages of early lymphoid development. J Exp Med 194:127-134 
6. Godfrey DI, Kennedy J, Suda T, Zlotnik A (1993) A developmental pathway involving four phenotypically and functionally distinct subsets of CD3-CD4-CD8- triple-negative adult mouse thymocytes defined by CD44 and CD25 expression. J Immunol 150:4244-4252

7. Radtke F, Wilson A, Stark G et al (1999) Deficient $\mathrm{T}$ cell fate specification in mice with an induced inactivation of Notch1. Immunity 10:547-558

8. Von Freeden-Jeffry U, Vieira P, Lucian LA et al (1995) Lymphopenia in interleukin (IL)-7 gene-deleted mice identifies IL-7 as a nonredundant cytokine. J Exp Med 181:1519-1526

9. Ceredig R, Rolink T (2002) A positive look at double-negative thymocytes. Nat Rev Immunol 2:888-897

10. Porritt HE, Rumfelt LL, Tabrizifard S et al (2004) Heterogeneity among DN1 prothymocytes reveals multiple progenitors with different capacities to generate $\mathrm{T}$ cell and non-T cell lineages. Immunity 20:735-745

11. Raulet DH, Garman RD, Saito H, Tonegawa S (1985) Developmental regulation of T-cell receptor gene expression. Nature 314:103-107

12. Von Boehmer H, Fehling HJ (1997) Structure and function of the pre-T cell receptor. Annu Rev Immunol 15:433-452

13. Malissen B, Ardouin L, Lin SY et al (1999) Function of the CD3 subunits of the pre-TCR and TCR complexes during T cell development. Adv Immunol 72:103-148

14. Ciofani M, Zuniga-Pflucker JC (2005) Notch promotes survival of pre-T cells at the beta-selection checkpoint by regulating cellular metabolism. Nat Immunol 6:881-888

15. Yui MA, Rothenberg EV (2014) Developmental gene networks: a triathlon on the course to T cell identity. Nat Rev Immunol 14:529-545

16. Rothenberg EV, Taghon T (2005) Molecular genetics of T cell development. Annu Rev Immunol 23:601-649

17. Ho IC, Tai TS, Pai SY (2009) GATA3 and the T-cell lineage: essential functions before and after T-helper-2-cell differentiation. Nat Rev Immunol 9:125-135

18. Rothenberg EV (2014) Transcriptional control of early T and B cell developmental choices. Annu Rev Immunol 32:283-321

19. Ikawa T, Fujimoto S, Kawamoto H et al (2001) Commitment to natural killer cells requires the helix-loop-helix inhibitor Id2. Proc Natl Acad Sci USA 98:5164-5169

20. Schwartz R, Engel I, Fallahi-Sichani M et al (2006) Gene expression patterns define novel roles for E47 in cell cycle progression, cytokine-mediated signaling, and T lineage development. Proc Natl Acad Sci USA 103:9976-9981

21. Del Real MM, Rothenberg EV (2013) Architecture of a lymphomyeloid developmental switch controlled by PU.1, Notch and Gata3. Development 140:1207-1219

22. Xu W, Carr T, Ramirez K et al (2013) E2A transcription factors limit expression of Gata3 to facilitate $\mathrm{T}$ lymphocyte lineage commitment. Blood 121:1534-1542

23. Hosoya T, Maillard I, Engel JD (2010) From the cradle to the grave: activities of GATA-3 throughout T-cell development and differentiation. Immunol Rev 238:110-125

24. Taghon T, Yui MA, Rothenberg EV (2007) Mast cell lineage diversion of T lineage precursors by the essential T cell transcription factor GATA-3. Nat Immunol 8:845-855

25. García-Ojeda ME, Wolterink RGJK, Lemâitre F et al (2013) GATA-3 promotes T-cell specification by repressing B-cell potential in pro-T cells in mice. Blood 121:1749-1759

26. Kishi H, Wei XC, Jin ZX et al (2000) Lineage-specific regulation of the murine RAG-2 promoter: GATA-3 in T cells and Pax-5 in B cells. Blood 95:3845-3852

27. Wang L, Wildt KF, Zhu J et al (2008) Distinct functions for the transcription factors GATA-3 and ThPOK during intrathymic differentiation of CD4(+) T cells. Nat Immunol 9:1122-1130

28. Staal FJ, Clevers HC (2005) WNT signalling and haematopoiesis: a WNT-WNT situation. Nat Rev Immunol 5:21-30 
29. Okamura RM, Sigvardsson M, Galceran J et al (1998) Redundant regulation of T cell differentiation and TCRalpha gene expression by the transcription factors LEF-1 and TCF-1. Immunity 8:11-20

30. Hattori N, Kawamoto H, Fujimoto S et al (1996) Involvement of transcription factors TCF-1 and GATA-3 in the initiation of the earliest step of T cell development in the thymus. J Exp Med 184:1137-1147

31. Germar K, Dose M, Konstantinou T et al (2011) T-cell factor 1 is a gatekeeper for T-cell specification in response to Notch signaling. Proc Natl Acad Sci 108:20060-20065

32. Weber BN, Chi AW, Chavez A et al (2011) A critical role for TCF-1 in T-lineage specification and differentiation. Nature 476:63-68

33. Verbeek S, Izon D, Hofhuis F et al (1995) An HMG-box-containing T-cell factor required for thymocyte differentiation. Nature 374:70-74

34. Schilham MW, Wilson A, Moerer P et al (1998) Critical involvement of Tcf-1 in expansion of thymocytes. J Immunol 161:3984-3991

35. Xu Y, Banerjee D, Huelsken J et al (2003) Deletion of beta-catenin impairs T cell development. Nat Immunol 4:1177-1182

36. Gounari F, Aifantis I, Khazaie K et al (2001) Somatic activation of beta-catenin bypasses pre-TCR signaling and TCR selection in thymocyte development. Nat Immunol 2:863-869

37. Xu M, Sharma A, Wiest DL, Sen JM (2009) Pre-TCR-induced beta-catenin facilitates traversal through beta-selection. J Immunol 182:751-758

38. Liu P, Li P, Burke S (2010) Critical roles of Bcl11b in T-cell development and maintenance of T-cell identity. Immunol Rev 238:138-149

39. Yui MA, Feng N, Rothenberg EV (2010) Fine-scale staging of T cell lineage commitment in adult mouse thymus. J Immunol 185:284-293

40. Ikawa T, Hirose S, Masuda K et al (2010) An essential developmental checkpoint for production of the $\mathrm{T}$ cell lineage. Science 329:93-96

41. Zhang S, Rozell M, Verma RK et al (2010) Antigen-specific clonal expansion and cytolytic effector function of CD8 $8^{+} \mathrm{T}$ lymphocytes depend on the transcription factor Bcl11b. J Exp Med 207:1687-1699

42. Vanvalkenburgh J, Albu DI, Bapanpally C et al (2011) Critical role of Bcl11b in suppressor function of T regulatory cells and prevention of inflammatory bowel disease. J Exp Med 208:2069-2081

43. Wakabayashi $\mathrm{Y}$, Watanabe $\mathrm{H}$, Inoue $\mathrm{J}$ et al (2003) Bcl11 b is required for differentiation and survival of alphabeta $\mathrm{T}$ lymphocytes. Nat Immunol 4:533-539

44. Albu DI, Feng D, Bhattacharya D et al (2007) BCL11B is required for positive selection and survival of double-positive thymocytes. J Exp Med 204:3003-3015

45. Li P, Burke S, Wang J et al (2010) Reprogramming of T cells to natural killer-like cells upon Bcl11b deletion. Science 329:85-89

46. Li L, Leid M, Rothenberg EV (2010) An early T cell lineage commitment checkpoint dependent on the transcription factor Bcl11b. Science 329:89-93

47. Zhang JA, Mortazavi A, Williams BA et al (2012) Dynamic transformations of genome-wide epigenetic marking and transcriptional control establish T cell identity. Cell 149:467-482

48. Mingueneau M, Kreslavsky T, Gray D et al (2013) The transcriptional landscape of $\alpha \beta$ T cell differentiation. Nat Immunol $14: 619-632$

49. Yashiro-Ohtani Y, He Y, Ohtani T et al (2009) Pre-TCR signaling inactivates Notch1 transcription by antagonizing E2A. Genes Dev 23:1665-1676

50. Engel I, Murre C (2004) E2A proteins enforce a proliferation checkpoint in developing thymocytes. EMBO J 23:202-211

51. Wojciechowski J, Lai A, Kondo M, Zhuang Y (2007) E2A and HEB are required to block thymocyte proliferation prior to pre-TCR expression. J Immunol 178:5717-5726 
52. Agata Y, Tamaki N, Sakamoto S et al (2007) Regulation of T cell receptor $\beta$ gene rearrangements and allelic exclusion by the Helix-Loop-Helix protein, E47. Immunity 27:871-884

53. Jones ME, Zhuang Y (2009) Regulation of V(D)J recombination by E-protein transcription factors. Adv Exp Med Biol 650:148-156

54. Kee BL (2009) E and ID proteins branch out. Nat Rev Immunol 9:175-184

55. Kim D, Peng XC, Sun XH (1999) Massive apoptosis of thymocytes in T-cell-deficient Id1 transgenic mice. Mol Cell Biol 19:8240-8253

56. Engel I, Johns C, Bain G et al (2001) Early thymocyte development is regulated by modulation of E2A protein activity. J Exp Med 194:733-745

57. Heemskerk MH, Blom B, Nolan G et al (1997) Inhibition of $\mathrm{T}$ cell and promotion of natural killer cell development by the dominant negative helix loop helix factor Id3. J Exp Med 186:1597-1602

58. Anderson MK, Hernandez-Hoyos G, Diamond RA, Rothenberg EV (1999) Precise developmental regulation of Ets family transcription factors during specification and commitment to the T cell lineage. Development 126:3131-3148

59. Eyquem S, Chemin K, Fasseu M, Bories JC (2004) The Ets-1 transcription factor is required for complete pre-T cell receptor function and allelic exclusion at the T cell receptor beta locus. Proc Natl Acad Sci USA 101:15712-15717

60. Lefebvre JM, Haks MC, Carleton MO et al (2005) Enforced expression of Spi-B reverses T lineage commitment and blocks beta-selection. J Immunol 174:6184-6194

61. Rothenberg EV, Moore JE, Yui MA (2008) Launching the T-cell-lineage developmental programme. Nat Rev Immunol 8:921

62. Levanon D, Groner Y (2004) Structure and regulated expression of mammalian RUNX genes. Oncogene 23:4211-4219

63. Egawa T, Tillman RE, Naoe Y et al (2007) The role of the Runx transcription factors in thymocyte differentiation and in homeostasis of naive T cells. J Exp Med 204:1945-1957

64. Talebian L, Li Z, Guo Y et al (2007) T-lymphoid, megakaryocyte, and granulocyte development are sensitive to decreases in CBF $\beta$ dosage. Blood 109:11-21

65. Ichikawa M, Asai T, Saito T et al (2004) AML-1 is required for megakaryocytic maturation and lymphocytic differentiation, but not for maintenance of hematopoietic stem cells in adult hematopoiesis. Nat Med 10:299-304

66. Growney JD, Shigematsu H, Li Z et al (2005) Loss of Runx1 perturbs adult hematopoiesis and is associated with a myeloproliferative phenotype. Blood 106:494-504

67. Woolf E, Xiao C, Fainaru O et al (2003) Runx3 and Runx1 are required for CD8 T cell development during thymopoiesis. Proc Natl Acad Sci USA 100:7731-7736

68. Merkenschlager M (2010) Ikaros in immune receptor signaling, lymphocyte differentiation, and function. FEBS Lett 584:4910-4914

69. Winandy S, Wu L, Wang JH, Georgopoulos K (1999) Pre-T cell receptor (TCR) and TCR-controlled checkpoints in T cell differentiation are set by Ikaros. J Exp Med 190:1039-1048

70. Dose M, Khan I, Guo Z et al (2006) c-Myc mediates pre-TCR-induced proliferation but not developmental progression. Blood 108:2669-2677

71. Douglas NC, Jacobs H, Bothwell AL, Hayday AC (2001) Defining the specific physiological requirements for c-Myc in T cell development. Nat Immunol 2:307-315

72. Hayden MS, West AP, Ghosh S (2006) NF-kappaB and the immune response. Oncogene 25:6758-6780

73. Gerondakis S, Fulford TS, Messina NL, Grumont RJ (2014) NF-кB control of T cell development. Nat Immunol 15:15-25

74. Voll RE, Jimi E, Phillips RJ et al (2000) NF-kappa B activation by the pre-T cell receptor serves as a selective survival signal in T lymphocyte development. Immunity 13:677-689 
75. Aifantis I, Gounari F, Scorrano L et al (2001) Constitutive pre-TCR signaling promotes differentiation through Ca mobilization and activation of NF- $\mathrm{\kappa B}$ and NFAT. Nat Immunol 2:403-409

76. Mandal M, Borowski C, Palomero T et al (2005) The BCL2A1 gene as a pre-T cell receptor-induced regulator of thymocyte survival. J Exp Med 201:603-614

77. Aifantis I, Mandal M, Sawai K et al (2006) Regulation of T-cell progenitor survival and cell-cycle entry by the pre-T-cell receptor. Immunol Rev 209:159-169

78. Kiani A, Rao A, Aramburu J (2000) Manipulating immune responses with immunosuppressive agents that target NFAT. Immunity 12:359-372

79. Macián F (2005) NFAT proteins: key regulators of T-cell development and function. Nat Rev Immunol 5:472-484

80. Serfling E, Avots A, Klein-Hessling S et al (2012) NFATc1/ $\alpha$ A: the other face of NFAT factors in lymphocytes. Cell Commun Signal 10:16

81. Crabtree GR (1999) Generic signals and specific outcomes: signaling through $\mathrm{Ca}^{2+}$, calcineurin, and NF-AT. Cell 96:611614

82. Hogan PG, Chen L, Nardone J, Rao A (2003) Transcriptional regulation by calcium, calcineurin, and NFAT. Genes Dev $17: 2205-2232$

83. Bueno OF, Brandt EB, Rothenberg ME, Molkentin JD (2002) Defective T cell development and function in calcineurin A beta -deficient mice. Proc Natl Acad Sci USA 99:9398-9403

84. Neilson JR, Winslow MM, Hur EM, Crabtree GR (2004) Calcineurin B1 is essential for positive but not negative selection during thymocyte development. Immunity 20:255-266

85. Ranger AM, Hodge MR, Gravallese EM et al (1998) Delayed lymphoid repopulation with defects in IL-4-driven responses produced by inactivation of NF-ATc. Immunity 8:125-134

86. Oukka M, Ho IC, de la Brousse FC et al (1998) The transcription factor NFAT4 is involved in the generation and survival of T cells. Immunity 9:295-304

87. Yoshida H, Nishina H, Takimoto H et al (1998) The transcription factor NF-ATc1 regulates lymphocyte proliferation and Th2 cytokine production. Immunity 8:115-124

88. Koltsova EK, Ciofani M, Benezra R et al (2007) Early growth response 1 and NF-ATc1 act in concert to promote thymocyte development beyond the beta-selection checkpoint. J Immunol 179:4694-4703

89. Canté-Barrett K, Winslow MM, Crabtree GR (2007) Selective role of NFATc3 in positive selection of thymocytes. J Immunol 179:103-110

90. Hayden-Martinez K, Kane LP, Hedrick SM (2000) Effects of a constitutively active form of calcineurin on T cell activation and thymic selection. J Immunol 165:3713-3721

91. Amasaki Y, Masuda ES, Imamura R et al (1998) Distinct NFAT family proteins are involved in the nuclear NFAT-DNA binding complexes from human thymocyte subsets. J Immunol 160:2324-2333

92. Patra AK, Avots A, Zahedi RP et al (2013) An alternative NFAT-activation pathway mediated by IL-7 is critical for early thymocyte development. Nat Immunol 14:127-135

93. Lopez-Rodriguez C, Aramburu J, Rakeman AS, Rao A (1999) NFAT5, a constitutively nuclear NFAT protein that does not cooperate with Fos and Jun. Proc Natl Acad Sci USA 96:7214-7219

94. Aramburu J, Drews-Elger K, Estrada-Gelonch A et al (2006) Regulation of the hypertonic stress response and other cellular functions by the Rel-like transcription factor NFAT5. Biochem Pharmacol 72:1597-1604

95. Buxadé M, Lunazzi G, Minguillón J et al (2012) Gene expression induced by Toll-like receptors in macrophages requires the transcription factor NFAT5. J Exp Med 209:379-393

96. Berga-Bolaños R, Alberdi M, Buxadé M et al (2013) NFAT5 induction by the pre-T-cell receptor serves as a selective survival signal in T-lymphocyte development. Proc Natl Acad Sci USA 110:16091-16096 
97. Villey I, De Chasseval R, De Villartay JP (1999) ROR $\gamma \mathrm{T}$, a thymus-specific isoform of the orphan nuclear receptor ROR $\gamma /$ TOR, is up-regulated by signaling through the pre-T cell receptor and binds to the TEA promoter. Eur J Immunol 29:4072 $-4080$

98. Sun Z, Unutmaz D, Zou YR et al (2000) Requirement for RORgamma in thymocyte survival and lymphoid organ development. Science 288:2369-2373

99. Lieu YK, Kumar A, Pajerowski AG et al (2004) Requirement of c-myb in T cell development and in mature T cell function. Proc Natl Acad Sci USA 101:14853-14858

100. Bender TP, Kremer CS, Kraus M et al (2004) Critical functions for c-Myb at three checkpoints during thymocyte development. Nat Immunol 5:721-729

101. Anderson MK (2006) At the crossroads: diverse roles of early thymocyte transcriptional regulators. Immunol Rev 209:191 $-211$

102. Reizis B, Leder P (2002) Direct induction of T lymphocyte-specific gene expression by the mammalian Notch signaling pathway. Genes Dev 16:295-300

103. Goldrath AW, Bevan MJ (1999) Selecting and maintaining a diverse T-cell repertoire. Nature 402:255-262

104. Starr TK, Jameson SC, Hogquist KA (2003) Positive and negative selection of T cells. Annu Rev Immunol 21:139-176

105. Zhang N, Hartig H, Dzhagalov I et al (2005) The role of apoptosis in the development and function of T lymphocytes. Cell Res 15:749-769

106. Chao DT, Korsmeyer SJ (1998) BCL-2 family: regulators of cell death. Annu Rev Immunol 16:395-419

107. Vander Heiden MG, Thompson CB (1999) Bcl-2 proteins: regulators of apoptosis or of mitochondrial homeostasis? Nat Cell Biol 1:E209-E216

108. Gross A, McDonnell JM, Korsmeyer SJ (1999) BCL-2 family members and the mitochondria in apoptosis. Genes Dev 13:1899-1911

109. Akashi K, Kondo M, von Freeden-Jeffry U et al (1997) Bcl-2 rescues T lymphopoiesis in interleukin-7 receptor-deficient mice. Cell 89:1033-1041

110. Maraskovsky E, O'Reilly LA, Teepe M et al (1997) Bcl-2 can rescue T lymphocyte development in interleukin-7 receptordeficient mice but not in mutant rag- $1^{-/-}$mice. Cell 89:1011-1019

111. Opferman JT, Letai A, Beard C et al (2003) Development and maintenance of B and T lymphocytes requires antiapoptotic MCL-1. Nature 426:671-676

112. Grillot DA, Merino R, Nunez G (1995) Bcl-XL displays restricted distribution during T cell development and inhibits multiple forms of apoptosis but not clonal deletion in transgenic mice. J Exp Med 182:1973-1983

113. Ma A, Pena JC, Chang B et al (1995) Bclx regulates the survival of double-positive thymocytes. Proc Natl Acad Sci USA 92:4763-4767

114. Motoyama N, Wang F, Roth KA et al (1995) Massive cell death of immature hematopoietic cells and neurons in Bcl-xdeficient mice. Science 267:1506-1510

115. Rathmell JC, Lindsten T, Zong W-X et al (2002) Deficiency in Bak and Bax perturbs thymic selection and lymphoid homeostasis. Nat Immunol 3:932-939

116. Lindsten T, Ross AJ, King A et al (2000) The combined functions of proapoptotic Bcl-2 family members Bak and Bax are essential for normal development of multiple tissues. Mol Cell 6:1389-1399

117. Wei MC, Zong WX, Cheng EH et al (2001) Proapoptotic BAX and BAK: a requisite gateway to mitochondrial dysfunction and death. Science 292:727-730

118. Yücel R, Karsunky H, Klein-Hitpass L, Möröy T (2003) The transcriptional repressor Gfil affects development of early, uncommitted c-Kit + T cell progenitors and CD4/CD8 lineage decision in the thymus. J Exp Med 197:831-844

119. Phelan JD, Saba I, Zeng H et al (2013) Growth factor independent-1 maintains Notch1-dependent transcriptional programming of lymphoid precursors. PLoS Genet 9:e1003713 
120. Grimes HL, Gilks CB, Chan TO et al (1996) The Gfi-1 protooncoprotein represses Bax expression and inhibits T-cell death. Proc Natl Acad Sci USA 93:14569-14573

121. Schmidt T, Karsunky H, Rödel B et al (1998) Evidence implicating Gfi-1 and Pim-1 in pre-T-cell differentiation steps associated with $\beta$-selection. EMBO J 17:5349-5359

122. Huang DC, Strasser A (2000) BH3-Only proteins-essential initiators of apoptotic cell death. Cell 103:839-842

123. Marsden VS, Strasser A (2003) Control of apoptosis in the immune system: Bcl-2, BH3-only proteins and more. Annu Rev Immunol 21:71-105

124. Haks MC, Krimpenfort P, van den Brakel JH, Kruisbeek AM (1999) Pre-TCR signaling and inactivation of p53 induces crucial cell survival pathways in pre-T cells. Immunity 11:91-101

125. Bogue MA, Zhu C, Aguilar-Cordova E et al (1996) p53 is required for both radiation-induced differentiation and rescue of $\mathrm{V}(\mathrm{D}) \mathrm{J}$ rearrangement in scid mouse thymocytes. Genes Dev 10:553-565

126. Guidos CJ, Williams CJ, Grandal I et al (1996) V(D)J recombination activates a p53-dependent DNA damage checkpoint in scid lymphocyte precursors. Genes Dev 10:2038-2054

127. Costello PS, Cleverley SC, Galandrini R et al (2000) The GTPase rho controls a p53-dependent survival checkpoint during thymopoiesis. J Exp Med 192:77-85

128. Oda E, Ohki R, Murasawa H et al (2000) Noxa, a BH3-only member of the Bcl-2 family and candidate mediator of p53induced apoptosis. Science 288:1053-1058

129. Nakano K, Vousden KH (2001) PUMA, a novel proapoptotic gene, is induced by p53. Mol Cell 7:683-694

130. Yu J, Zhang L, Hwang PM et al (2001) PUMA induces the rapid apoptosis of colorectal cancer cells. Mol Cell 7:673-682

131. Mandal M, Crusio KM, Meng F et al (2008) Regulation of lymphocyte progenitor survival by the proapoptotic activities of Bim and Bid. Proc Natl Acad Sci USA 105:20840-20845

132. Peschon JJ, Morrissey PJ, Grabstein KH et al (1994) Early lymphocyte expansion is severely impaired in interleukin 7 receptor-deficient mice. J Exp Med 180:1955-1960

133. Hare KJ, Jenkinson EJ, Anderson G (2000) An essential role for the IL-7 receptor during intrathymic expansion of the positively selected neonatal T cell repertoire. J Immunol 165:2410-2414

134. Pallard C, Stegmann AP, van Kleffens T et al (1999) Distinct roles of the phosphatidylinositol 3-kinase and STAT5 pathways in IL-7-mediated development of human thymocyte precursors. Immunity 10:525-535

135. Maillard I, Adler SH, Pear WS (2003) Notch and the immune system. Immunity 19:781-791

136. Koch U, Fiorini E, Benedito R et al (2008) Delta-like 4 is the essential, nonredundant ligand for Notch 1 during thymic $\mathrm{T}$ cell lineage commitment. J Exp Med 205:2515-2523

137. Thompson PK, Zúñiga-Pflücker JC (2011) On becoming a T cell, a convergence of factors kick it up a Notch along the way. Semin Immunol 23:350-359

138. Kopan R, Ilagan MX (2009) The canonical Notch signaling pathway: unfolding the activation mechanism. Cell 137:216233

139. Pui JC, Allman D, Xu L et al (1999) Notch1 expression in early lymphopoiesis influences B versus T lineage determination. Immunity 11:299-308

140. Wolfer A, Wilson A, Nemir M et al (2002) Inactivation of Notch1 impairs VDJbeta rearrangement and allows pre-TCRindependent survival of early alpha beta Lineage Thymocytes. Immunity 16:869-879

141. Ciofani M, Knowles GC, Wiest DL et al (2006) Stage-specific and differential Notch dependency at the $\alpha \beta$ and $\gamma \delta \mathrm{T}$ lineage bifurcation. Immunity 25:105-116

142. Xiong J, Armato MA, Yankee TM (2011) Immature single-positive CD $8^{+}$thymocytes represent the transition from Notchdependent to Notch-independent T-cell development. Int Immunol 23:55-64

143. Laky K, Fowlkes BJ (2008) Notch signaling in CD4 and CD8 T cell development. Curr Opin Immunol 20:197-202 
144. Yuan JS, Kousis PC, Suliman S et al (2010) Functions of notch signaling in the immune system: consensus and controversies. Annu Rev Immunol 28:343-365

145. Dudley EC, Petrie HT, Shah LM et al (1994) T cell receptor beta chain gene rearrangement and selection during thymocyte development in adult mice. Immunity 1:83-93

146. Taghon T, Yui MA, Pant R et al (2006) Developmental and molecular characterization of emerging beta- and gammadeltaselected pre-T cells in the adult mouse thymus. Immunity 24:53-64

147. Tsai FY, Orkin SH (1997) Transcription factor GATA-2 is required for proliferation/survival of early hematopoietic cells and mast cell formation, but not for erythroid and myeloid terminal differentiation. Blood 89:3636-3643

148. Laiosa CV, Stadtfeld M, Xie H et al (2006) Reprogramming of committed T cell progenitors to macrophages and dendritic cells by C/EBP alpha and PU.1 transcription factors. Immunity 25:731-744

149. DeKoter RP, Singh H (2000) Regulation of B lymphocyte and macrophage development by graded expression of PU.1. Science 288:1439-1441

150. Braunstein M, Rajkumar P, Claus CL et al (2010) HEBAlt enhances the T-cell potential of fetal myeloid-biased precursors. Int Immunol 22:963-972

151. Grawunder U, West RB, Lieber MR (1998) Antigen receptor gene rearrangement. Curr Opin Immunol 10:172-180

152. Mallick CA, Dudley EC, Viney JL et al (1993) Rearrangement and diversity of T cell receptor beta chain genes in thymocytes: a critical role for the beta chain in development. Cell 73:513-519

153. Michie AM, Zuniga-Pflucker JC (2002) Regulation of thymocyte differentiation: pre-TCR signals and beta-selection. Semin Immunol 14:311-323

154. Gellert M (2002) V(D)J recombination: RAG proteins, repair factors, and regulation. Annu Rev Biochem 71:101-132

155. Brady BL, Steinel NC, Bassing CH (2010) Antigen receptor allelic exclusion: an update and reappraisal. J Immunol $185: 3801-3808$

156. Kruisbeek AM, Haks MC, Carleton M et al (2000) Branching out to gain control: how the pre-TCR is linked to multiple functions. Immunol Today 21:637-644

157. Von Boehmer H (2005) Unique features of the pre-T-cell receptor alpha-chain: not just a surrogate. Nat Rev Immunol $5: 571-577$

158. Von Boehmer H, Aifantis I, Azogui O et al (1999) The impact of pre-T-cell receptor signals on gene expression in developing T cells. Cold Spring Harb Symp Quant Biol 64:283-289

159. Saint-Ruf C, Panigada M, Azogui O et al (2000) Different initiation of pre-TCR and gammadeltaTCR signalling. Nature 406:524-527

160. Aifantis I, Azogui O, Feinberg J et al (1998) On the role of the pre-T cell receptor in alphabeta versus gammadelta $\mathrm{T}$ lineage commitment. Immunity 9:649-655

161. Snodgrass HR, Dembić Z, Steinmetz M, von Boehmer H (1985) Expression of T-cell antigen receptor genes during fetal development in the thymus. Nature 315:232-233

162. Von Boehmer H (1990) Developmental biology of T cells in T cell-receptor transgenic mice. Annu Rev Immunol 8:531556

163. Kishi H, Borgulya P, Scott B et al (1991) Surface expression of the beta T cell receptor (TCR) chain in the absence of other TCR or CD3 proteins on immature T cells. EMBO J 10:93-100

164. Shinkai Y, Koyasu S, Nakayama K et al (1993) Restoration of T cell development in RAG-2-deficient mice by functional TCR transgenes. Science 259:822-825

165. Mombaerts P, Clarke AR, Rudnicki MA et al (1992) Mutations in T-cell antigen receptor genes alpha and beta block thymocyte development at different stages. Nature 360:225-231

166. Haks MC, Lefebvre JM, Lauritsen JPH et al (2005) Attenuation of gammadeltaTCR signaling efficiently diverts thymocytes to the alphabeta lineage. Immunity 22:595-606 
167. Hayes SM, Li L, Love PE (2005) TCR signal strength influences $\alpha \beta / \gamma \delta$ lineage fate. Immunity 22:583-593

168. Panigada M, Porcellini S, Barbier E et al (2002) Constitutive endocytosis and degradation of the pre-T cell receptor. J Exp Med 195:1585-1597

169. Tremblay M, Herblot S, Lecuyer E, Hoang T (2003) Regulation of pT alpha gene expression by a dosage of E2A, HEB, and SCL. J Biol Chem 278:12680-12687

170. Trop S, Rhodes M, Wiest DL et al (2000) Competitive displacement of $\mathrm{pT}$ alpha by TCR-alpha during TCR assembly prevents surface coexpression of pre-TCR and alpha beta TCR. J Immunol 165:5566-5572

171. Yamasaki S, Saito T (2007) Molecular basis for pre-TCR-mediated autonomous signaling. Trends Immunol 28:39-43

172. Yamasaki S, Ishikawa E, Sakuma M et al (2006) Mechanistic basis of pre-T cell receptor-mediated autonomous signaling critical for thymocyte development. Nat Immunol 7:67-75

173. Aifantis I, Borowski C, Gounari F et al (2002) A critical role for the cytoplasmic tail of pTalpha in T lymphocyte development. Nat Immunol 3:483-488

174. Ciofani M, Schmitt TM, Ciofani A et al (2004) Obligatory role for cooperative signaling by pre-TCR and Notch during thymocyte differentiation. J Immunol 172:5230-5239

175. Trampont PC, Tosello-Trampont AC, Shen Y et al (2010) CXCR4 acts as a costimulator during thymic beta-selection. Nat Immunol 11:162-170

176. Janas ML, Varano G, Gudmundsson K et al (2010) Thymic development beyond beta-selection requires phosphatidylinositol 3-kinase activation by CXCR4. J Exp Med 207:247-261

177. Staal FJ, Clevers HC (2003) Wnt signaling in the thymus. Curr Opin Immunol 15:204-208

178. Goux D, Coudert JD, Maurice D et al (2005) Cooperating pre-T-cell receptor and TCF-1-dependent signals ensure thymocyte survival. Blood 106:1726-1733

179. Borowski C, Li X, Aifantis I et al (2004) Pre-TCRalpha and TCRalpha are not interchangeable partners of TCRbeta during T lymphocyte development. J Exp Med 199:607-615

180. Von Boehmer H, Aifantis I, Feinberg J et al (1999) Pleiotropic changes controlled by the pre-T-cell receptor. Curr Opin Immunol 11:135-142

181. Groves T, Smiley P, Cooke MP et al (1996) Fyn can partially substitute for Lck in T lymphocyte development. Immunity $5: 417-428$

182. Palacios EH, Weiss A (2004) Function of the Src-family kinases, Lck and Fyn, in T-cell development and activation. Oncogene 23:7990-8000

183. Cheng AM, Negishi I, Anderson SJ et al (1997) The Syk and ZAP-70 SH2-containing tyrosine kinases are implicated in pre-T cell receptor signaling. Proc Natl Acad Sci USA 94:9797-9801

184. Pivniouk V, Tsitsikov E, Swinton P et al (1998) Impaired viability and profound block in thymocyte development in mice lacking the adaptor protein SLP-76. Cell 94:229-238

185. Palacios EH, Weiss A (2007) Distinct roles for Syk and ZAP-70 during early thymocyte development. J Exp Med 204:1703 $-1715$

186. Fayard E, Moncayo G, Hemmings BA, Hollander GA (2010) Phosphatidylinositol 3-kinase signaling in thymocytes: the need for stringent control. Sci Signal 3:5

187. Juntilla MM, Wofford JA, Birnbaum MJ et al (2007) Akt1 and Akt2 are required for alphabeta thymocyte survival and differentiation. Proc Natl Acad Sci USA 104:12105-12110

188. Brunet A, Bonni A, Zigmond MJ et al (1999) Akt promotes cell survival by phosphorylating and inhibiting a Forkhead transcription factor. Cell 96:857-868

189. Kelly AP, Finlay DK, Hinton HJ et al (2007) Notch-induced T cell development requires phosphoinositide-dependent kinase 1. EMBO J 26:3441-3450 
190. Aramburu J, Rao A, Klee CB (2000) Calcineurin: from structure to function. Curr Top Cell Regul 36:237-295

191. Tan S-L, Parker PJ (2003) Emerging and diverse roles of protein kinase C in immune cell signalling. Biochem J 376:545552

192. Hayashi K, Altman A (2007) Protein kinase C theta (PKCtheta): a key player in T cell life and death. Pharmacol Res $55: 537-544$

193. Felli MP, Vacca A, Calce A et al (2005) PKC theta mediates pre-TCR signaling and contributes to Notch3-induced T-cell leukemia. Oncogene 24:992-1000

194. Michie AM, Soh JW, Hawley RG et al (2001) Allelic exclusion and differentiation by protein kinase C-mediated signals in immature thymocytes. Proc Natl Acad Sci USA 98:609-614

195. Rincon M, Flavell RA, Davis RJ (2001) Signal transduction by MAP kinases in T lymphocytes. Oncogene 20:2490-2497

196. Iritani BM, Alberola-Lla J, Forbush KA, Perlmutter RM (1999) Distinct signals mediate maturation and allelic exclusion in lymphocyte progenitors. Immunity 10:713-722

197. Carleton M, Haks MC, Smeele SA et al (2002) Early growth response transcription factors are required for development of CD4(-)CD8(-) thymocytes to the CD4(+)CD8(+) stage. J Immunol 168:1649-1658

198. Xi H, Kersh GJ (2004) Sustained early growth response gene 3 expression inhibits the survival of CD4/CD8 doublepositive thymocytes. J Immunol 173:340-348

199. Miyazaki T (1997) Two distinct steps during thymocyte maturation from CD4- CD8 - to CD4+ CD8+ distinguished in the early growth response (Egr)-1 transgenic mice with a recombinase-activating gene-deficient background. J Exp Med 186:877885

200. Bain G, Cravatt CB, Loomans C et al (2001) Regulation of the helix-loop-helix proteins, E2A and Id3, by the Ras-ERK MAPK cascade. Nat Immunol 2:165-171

201. Engel I, Murre C (2002) Disruption of pre-TCR expression accelerates lymphomagenesis in E2A-deficient mice. Proc Natl Acad Sci USA 99:11322-11327

202. Xi H, Schwartz R, Engel I et al (2006) Interplay between RORgammat, Egr3, and E proteins controls proliferation in response to pre-TCR signals. Immunity $24: 813-826$

203. Lin WC, Desiderio S (1994) Cell cycle regulation of V(D)J recombination-activating protein RAG-2. Proc Natl Acad Sci USA 91:2733-2737

204. De la Cueva E, García-Cao I, Herranz M et al (2006) Tumorigenic activity of p21Waf1/Cip1 in thymic lymphoma. Oncogene 25:4128-4132

205. El-Deiry WS, Tokino T, Velculescu VE et al (1993) WAF1, a potential mediator of p53 tumor suppression. Cell 75:817825

206. Stahl M, Dijkers PF, Kops GJ et al (2002) The forkhead transcription factor FoxO regulates transcription of p27Kip1 and Bim in response to IL-2. J Immunol 168:5024-5031

207. Mombaerts P, Terhorst C, Jacks T et al (1995) Characterization of immature thymocyte lines derived from T-cell receptor or recombination activating gene 1 and p53 double mutant mice. Proc Natl Acad Sci USA 92:7420-7424

208. Rashkovan M, Vadnais C, Ross J et al (2014) Miz-1 regulates translation of Trp53 via ribosomal protein L22 in cells undergoing V(D)J recombination. Proc Natl Acad Sci USA 111:E5411-E5419

209. Anderson SJ, Lauritsen JPH, Hartman MG et al (2007) Ablation of ribosomal protein L22 selectively impairs alphabeta T cell development by activation of a p53-dependent checkpoint. Immunity 26:759-772

210. Stadanlick JE, Zhang Z, Lee S-Y et al (2011) Developmental arrest of T cells in Rpl22-deficient mice is dependent upon multiple p53 effectors. J Immunol 187:664-675

211. Saba I, Kosan C, Vassen L et al (2011) Miz-1 is required to coordinate the expression of TCRbeta and p53 effector genes at the pre-TCR "beta-selection" checkpoint. J Immunol 187:2982-2992 
212. Sicinska E, Aifantis I, Le Cam L et al (2003) Requirement for cyclin D3 in lymphocyte development and T cell leukemias. Cancer Cell 4:451-461

213. Lara-Astiaso D, Weiner A, Lorenzo-Vivas E et al (2014) Chromatin state dynamics during blood formation. Science 345:943-949

214. Buenrostro JD, Giresi PG, Zaba LC et al (2013) Transposition of native chromatin for fast and sensitive epigenomic profiling of open chromatin, DNA-binding proteins and nucleosome position. Nat Methods 10:1213-1218 